\title{
Propolis Components and Biological Activities from Stingless Bees Collected on South Sulawesi, Indonesia
}

\author{
Ryo Miyata ${ }^{1}$, Muhamad Sahlan², Yoshinobu Ishikawa', Hiroshi Hashimoto', Sari Honda', Shigenori Kumazawa1* \\ ${ }^{1}$ Graduate School of Integrated Pharmaceutical and Nutritional Sciences, University of Shizuoka, Shizuoka, Japan \\ ${ }^{2}$ Department of Chemical Engineering, Faculty of Engineering, Universitas Indonesia, Depok, Indonesia
}

\section{ARTICLE INFO}

Article history:

Received September 20, 2018

Received in revised form October 10, 2019

Accepted October 20, 2019

KEYWORDS:

propolis,

Indonesia,

podophyllotoxin derivatives,

chromanone,

xanthine oxidase

\begin{abstract}
Three new compounds, namely sulabiroins A (1) and B (2), and 2',3'-dihydro-3'hydroxypapuanic acid (3), were isolated from the propolis of stingless bees (Tetragonula aff. biroi) collected on South Sulawesi, Indonesia. In addition, ten known compounds, (-)-papuanic acid (4), (-)-isocalolongic acid (5), isopapuanic acid (6), isocalopolyanic acid (7), glyasperin A (8), broussoflavonol F (9), (2S)-5,7-dihydroxy-4'-methoxy-8prenylflavanone (10), isorhamnetin (11), (1'S)-2-trans,4-trans-abscisic acid (12), and (1'S)-2-cis,4-trans-abscisic acid (13) were identified. The structures of the new and known compounds were determined by spectroscopic analysis. The absolute configurations of sulabiroins A (1) and B (2) were determined by X-ray crystallography analysis and ECD calculation, respectively. The propolis from stingless bee (Tetragonula aff. biroi) collected on South Sulawesi contained compounds not present in propolis from other regions. Sulabiroin $A$ (1) and isorhamnetin (11) were examined for xanthine oxidase (XO) inhibitory activity as one of biological activities; isorhamnetin (11) exhibited potent $\mathrm{XO}$ inhibitory activity, with an $\mathrm{IC}_{50}$ value of $3.9 \mu \mathrm{M}$.
\end{abstract}

\section{Introduction}

Propolis is a resinous hive product collected from different plant sources by honeybees, Apis mellifera. Propolis has a variety of biological activities, including antibacterial, anti-inflammatory, antioxidant, and anticancer properties, and is used as a folk medicine in many regions of the world (Marcucci 1995; Bankova et al. 2000; Banskota et al. 2001). Generally, propolis is used in foods, beverages, and supplements to improve health and prevent conditions such as inflammation, heart disease, and cancer, as well as in cosmetics (Lotfy 2006; Salantino et al. 2011; Sforcin and Bankova 2011).

Propolis usually contains a rich variety of chemical compounds such as polyphenols, terpenoids, steroids, and amino acids, depending on the vegetation at the collection site. Geographical location has a bearing on the chemical composition, thus imparting distinctive qualities to propolis. For example, green propolis from Minas Gerais State, Brazil, contains many terpenoids and prenylated derivatives of p-coumaric acid, particularly artepillin $C$ and $(E)-3-$ prenyl-4-(dihydrocinnamoyloxy)-cinnamic acid, as

\footnotetext{
* Corresponding Author

E-mail Address: kumazawa@u-shizuoka-ken.ac.jp
}

the young leaves of Baccharis dracunculifolia are the propolis source (Kumazawa et al. 2003). On the other hand, propolis from Europe and China contains many flavonoids and phenolic acid esters, such as chrysin, pinocembrin, and caffeic acid phenethyl ester, as the bud exudates of Populus species are the major propolis source (Kumazawa et al. 2002, 2004b). Salantino et al. (2011) have stated that although the focus of propolis research centered mainly on Brazilian green propolis and poplar propolis, propolis collected on many other regions are also promising. Previously, we found that Macaranga tanarius is the source of propolis from Okinawa, which is the southernmost prefecture of Japan. Okinawan propolis contains many prenyl flavonoids that exhibit strong antioxidant activities and are not present in the propolis from other regions (Kumazawa et al. 2004a). Furthermore, differences in plant origins also affect propolis properties, such as biological activity, texture, flavor, and color.

In this study, we aimed to examine the propolis from stingless bees. Stingless bees belong to the Meliponini tribe (Bankova and Popova 2007). There are more than 300 reported species in the Meliponini tribe, which are found in tropical regions of the world (Chinh and Sommeijer 2005). The nests of Apis mellifera honeybees are made from their beeswax, 
and their hives are coated with propolis as a sealant. On the other hand, the nests of stingless bees are constructed of propolis, since stingless bees do not produce hexagonal beeswax combs. The entire nests of stingless bees in tropical regions are referred to as "propolis" and used as the ingredients of soaps and mouthwashes. Despite this, the propolis from stingless bees has not been well studied.

With this in mind, the components of propolis from stingless bees (Tetragonula aff. biroi) collected on South Sulawesi, Indonesia, and their biological activities, were studied to assess their potential utility. Three new compounds (1-3) and ten known compounds were isolated, and their structures were determined by spectroscopic analysis. In addition, the absolute configurations of sulabiroins $A(1)$ and B (2) were determined by X-ray structure analysis and electronic circular dichroism (ECD) calculation, respectively. Moreover, some of the isolated compounds were tested for xanthine oxidase (XO) inhibitory activity. Herein, we report the structures of the isolated compounds from the propolis, as well as $\mathrm{XO}$ inhibitory activity testing.

\section{Materials and Methods}

\subsection{General Experimental Procedures}

Optical rotation values were measured using a DIP-1000 digital polarimeter (Jasco, Tokyo, Japan). ECD spectra were obtained using J-600 and J-820 spectrometer (Jasco). IR spectra were recorded by a FT/IR-550 spectrometer (Jasco). UV-Vis spectra were acquired using a V-560 UV/VIS spectrophotometer (Jasco). HRESIMS spectra were acquired on a Thermo Fisher Scientific Q-Exactive HR-ESI-Orbitrap-MS (Thermo Fisher Scientific Inc., MA), while 1D and 2D NMR spectra were acquired on a Bruker Biospin AVANCE-III ( $400 \mathrm{MHz}$ ) spectrometer (Bruker BioSpin, Rheinstetten, Germany), with chemical shifts expressed in ppm. Silica-gel column chromatography was carried out using silica gel 60N (230-400 mesh, Kanto Chemical, Tokyo, Japan). For RP-HPLC separations with a recycling system, a PU-1586 Intelligent prep pump (Jasco), UV8010 detector (Tosoh, Tokyo, Japan), CAPCELL PAK UG 120 C18 column $(5 \mu \mathrm{m}, 20 \times 250$ mm, Shiseido, Tokyo, Japan), Shiseido CAPCELL PAKUG120 C18 column (5 $\mu \mathrm{m}$, $10 \times 250 \mathrm{~mm}$ ), Shiseido CAPCELL PAK ACR C18 column (5 $\mu \mathrm{m}, 20 \times 250 \mathrm{~mm}$ ), and HPLC-grade solvents were used. For qualitative analysis, an instrument equipped with a PU-980 intelligent HPLC pump (Jasco), UV-970 Plus intelligent UV/VIS detector (Jasco) and a CAPCELL PAK C18 UG 120 column ( $5 \mu \mathrm{m}, 4.6$ x $250 \mathrm{~mm}$, Shiseido) were used. For XO inhibitory assay, an instrument equipped with a PU-2089 Plus quaternary gradient pump (Jasco Co., Inc.), MD-4017 photo diode array detector (Jasco), AS-4050 HPLC autosampler (Jasco) and a CAPCELL PAK

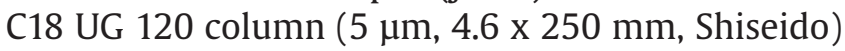
were used.

\subsection{Biological Material}

Stingless bee propolis (Tetragonula aff. biroi) was collected in December 2015 in North Luwu, South Sulawesi Province, Indonesia. The stingless bee species was identified by Dr. Sih Kahono from Laboratorium Entomologi, Museum Zoologicum Bogorience, Pusat Penelitian Biologi LIPI (Entomology Laboratory, Museum Zoologicum Bogorience, Biology Research Center, The Indonesia Science Institute). A voucher sample of the propolis (1512RPPD01) studied in this paper has been deposited at PT RIN Biotek Indonesia, South Tangerang, Banten, Indonesia.

\subsection{Extraction and Isolation}

Stingless bee propolis (100 g) was extracted with $70 \% \mathrm{EtOH}(1.3 \mathrm{l}$ ) with stirring at room temperature for $24 \mathrm{~h}$, after which the solids were removed by filtration. The filtrates were concentrated at reduced pressure to give an EtOH extract ( $25 \mathrm{~g}$ ). This extract was suspended in $\mathrm{H}_{2} \mathrm{O}(300 \mathrm{ml})$ and successively partitioned with $n$-hexane $(2 \times 300 \mathrm{ml})$ and $\operatorname{EtOAc}(2 \times 300 \mathrm{ml})$ to give $n$-hexane- (6.1 g), EtOAc- $(4.1 \mathrm{~g})$, and $\mathrm{H}_{2} \mathrm{O}$-soluble extracts, respectively. The $n$-hexane-soluble fraction (6.1 g) was subjected to silica-gel column chromatography (20 $400 \mathrm{~mm}$ ), with $n$-hexane/EtOAc-MeOH gradient mixtures ( $4: 1,850 \mathrm{ml} ; 3: 1,1,250 \mathrm{ml} ; 2: 1,200 \mathrm{ml} ; 1: 1$, $400 \mathrm{ml} ; 0: 1,200 \mathrm{ml}$; MeOH $400 \mathrm{ml}$ ) as eluents by 200 $\mathrm{ml}$ for each fractions, to yield 17 fractions (fr. 1, $799 \mathrm{mg}$; fr. 2, 2.44 g; fr. 3, $289 \mathrm{mg}$; fr. 4, $790 \mathrm{mg}$; fr. 5, $130 \mathrm{mg}$; fr. 6, $314 \mathrm{mg}$; fr. 7, $14 \mathrm{mg}$; fr. 8, $211 \mathrm{mg}$; fr. 9, $16 \mathrm{mg}$; fr. 10, $75 \mathrm{mg}$; fr. 11, $30 \mathrm{mg}$; fr. 12, $214 \mathrm{mg}$; fr. 13, $54 \mathrm{mg}$; fr. 14, $148 \mathrm{mg}$; fr. 15, $12 \mathrm{mg}$; fr. 16, $392 \mathrm{mg}$; fr. 17, 241 $\mathrm{mg})$. The EtOAc-soluble fraction $(4.1 \mathrm{~g})$ was subjected to silica-gel column chromatography $(30 \times 500 \mathrm{~mm})$, with $n$-hexane/EtOAc-MeOH gradient mixtures ( $4: 1,400$ $\mathrm{ml} ; 3: 1,500 \mathrm{ml} ; 2: 1,300 \mathrm{ml} ; 1: 1,300 \mathrm{ml} ; 0: 1,300 \mathrm{ml}$; $\mathrm{MeOH} 300 \mathrm{ml}$ ) as eluents by $200 \mathrm{ml}$ for each fraction, to yield nine fractions (fr. 18, $226 \mathrm{mg}$; fr. 19, $1.03 \mathrm{~g}$; fr. 20, 404 mg; fr. 21, 237 mg; fr. 22, 453 mg; fr. 23, 222 mg; fr. 24, 564 mg; fr. 25, $268 \mathrm{mg}$; fr. 26, $853 \mathrm{mg}$ ). Fraction 3 was subjected to preparative RP-HPLC with $\mathrm{H}_{2} \mathrm{O}-\mathrm{MeCN}$ (25:75, 0.1\% TFA (trifluoroacetic acid)) as the eluent to give 7 (2.8 mg, Rt (Retention time):30 min). Fraction 4 was subjected to preparative RP-HPLC with $\mathrm{H}_{2} \mathrm{O}-\mathrm{MeCN}$ (25:75, 0.1\% TFA) as the eluent to give 4 ( $39.7 \mathrm{mg}$, Rt:40 
min), 5 (9.0 mg, Rt:25 min), and 6 (2.8 mg, Rt:35 min). Fraction 6 was subjected to preparative RP-HPLC with $\mathrm{H}_{2} \mathrm{O}-\mathrm{MeCN}(40: 60,0.1 \%$ TFA) as the eluent to give 10 (1.3 $\mathrm{mg}, \mathrm{Rt}: 15 \mathrm{~min})$ and 1 (31.9 mg, Rt:10 min). Fraction 8 was subjected to preparative RP-HPLC with $\mathrm{H}_{2} \mathrm{O}-\mathrm{MeCN}$ (40:60, 0.1\% TFA) as the eluent to give 8 ( $6.8 \mathrm{mg}$, Rt:50 min), 9 (6.8 mg, Rt:30 min), and 2 (3.1 mg, Rt:15 min). Fractions 11-13 were subjected to preparative RP-HPLC with $\mathrm{H}_{2} \mathrm{O}-\mathrm{MeCN}(40: 60,0.1 \%$ TFA) as the eluent to give 3 (2.3 mg, Rt:30 min). Fraction 22 was subjected to preparative RP-HPLC with $\mathrm{H}_{2} \mathrm{O}-\mathrm{MeCN}(75: 25,0.1 \%$ TFA) as the eluent to give 2 (17.0 $\mathrm{mg}$, Rt: $15 \mathrm{mg}$ ). Fraction 24 was subjected to preparative RP-HPLC with $\mathrm{H}_{2} \mathrm{O}-\mathrm{MeCN}$ (75:25, 0.1\% TFA) as the eluent to give 12 (3.6 mg, Rt:20 $\mathrm{min}$ ) and 13 (3.9 mg, Rt:25 min) followed by 11 (7.7 $\mathrm{mg}$, Rt:15 min) with $\mathrm{H}_{2} \mathrm{O}-\mathrm{MeCN}$ (50:50, 0.5\% TFA) as the eluent. All preparative RP-HPLC separations were performed at a flow rate of $10 \mathrm{ml} / \mathrm{min}$ and compounds were detected at a wavelength of $270 \mathrm{~nm}$. The purity by HPLC of all isolated compounds at a wavelength of $270 \mathrm{~nm}$ is $>98 \%$.

\subsection{X-ray Crystallographic Data for 1}

Crystals of compound 1 were obtained from 2-propanol, and the absolute configuration of 1 was determined from data collected on a Rigaku XtalLAB Synergy-S diffractometer with $\mathrm{Cu} \mathrm{K} \alpha$ radiation $(\lambda=$ 1.54187 ) at $T=100.2(5) \mathrm{K}$. The structure was solved by the SHELXT method and refined based on fullmatrix least-squares on $F^{2}$ using SHELXL (Sheldrick 2015). Crystallographic data for sulabiroin A (1): plates, colorless, crystal size $0.343 \times 0.077 \times 0.040 \mathrm{~mm}$, $\mathrm{C}_{22} \mathrm{H}_{22} \mathrm{O}_{7}, \mathrm{M}=398.39$, monoclinic space group, $P 2_{1}, a=$ $11.01570(10) \AA, b=6.75950(10) \AA, c=13.03660(10) \AA, \beta$ $=106.3730(10)^{\circ}, V=931.348(18) \AA 3, Z=2, D_{\text {calcd }}=1.421$ $\mathrm{g} / \mathrm{m}^{3}, 37659$ collected reflections $\left(7.068^{\circ} \leq 2 \theta \leq 153.24^{\circ}\right)$, $\mu(\mathrm{Cu} \mathrm{K \alpha})=0.885 \mathrm{~mm}^{-1}, R_{1}=0.0322$ for $I \geq 2 \sigma(I)$, and $w \mathrm{R}_{2}$ $=0.0857$ (all data), $S=1.081$, Flack parameter $=-0.09(5)$, Hooft parameter $=-0.09(9)$. Crystallographic data for 2 have been deposited at the Cambridge Crystallographic Data Centre (CCDC number 1850729).

\subsection{ECD Calculations for 2}

3-Dimensional (3D) structure generation and conformational analysis of stereoisomers for 2 were carried out by use of a shell script previously reported (Ishikawa 2013). Briefly, 300 energy-minimized 3D structures of the stereoisomers were generated from the 2-dimensional chemical structures by Open Babel and Balloon (Vainio and Johnson 2007; O'Boyle et al. 2011; Sforcin and Bankova 2011). The single-point energy of each conformer was calculated with the PM7 Hamiltonian by MOPAC2016 (Stewart 2013). The several low-energy conformers were geometrically optimized with B3LYP/6-31G(d,p) level of density functional theory (DFT) in gas phase by Gaussian 09 (Frisch et al. 2013). The theoretical calculation of ECD was conducted with B3LYP/6-31G(d,p) level of timedependent density functional theory (TDDFT) in $\mathrm{MeOH}$ using the conductor-like polarizable continuum model (CPCM) by Gaussian 09. The calculated ECD data were processed and visualized by GaussView 5 .

\subsection{Qualitative Analysis of the Ethanol Extracts of Propolis}

The mobile phases consisted of $\mathrm{H}_{2} \mathrm{O}$ with $0.1 \%$ TFA (A) and MeCN with 0.1\% TFA (B). A linear gradient of $20-100 \%$ B over 50 min followed by $100 \%$ B from 50 to $60 \mathrm{~min}$ at a flow rate of $1 \mathrm{ml} / \mathrm{min}$ was used. The injection volume was $10 \mu$ l. The HPLC chromatograms are shown at $270 \mathrm{~nm}$.

\section{7. $X O$ Inhibitory Assays}

Allopurinol, xanthine, and xanthine oxidase were purchased from Sigma-Aldrich (St. Louis). The XO inhibitory assays were carried out following a slightly modified, previously reported method (Honda et al. 2017). The reaction medium, composed of $10 \mu \mathrm{l}$ of $1 \mathrm{~mm}$ xanthine in DMSO, and $160 \mu \mathrm{l}$ of $12.5 \mathrm{~mm}$ phosphate buffer ( $\mathrm{pH} 7.4$ ) was pre-incubated at $37^{\circ} \mathrm{C}$ for $5 \mathrm{~min}$. XO buffer solution $(0.020$ units $/ \mathrm{ml}, 20 \mu \mathrm{l})$ was added to the solution. After incubation at $37^{\circ} \mathrm{C}$ for $10 \mathrm{~min}$, $3 \%$ aqueous $\mathrm{HClO}_{4}(25 \mu \mathrm{l})$ was added to terminate the reaction. To quantify the amount of uric acid produced, an aliquot $(20 \mu \mathrm{l})$ of the solution was injected onto an HPLC column under the following conditions: column, $5 \mu \mathrm{m}, 4.6$ x $250 \mathrm{~mm}$, Shiseido CAPCELL PAKUG120 C18; flow rate, $1.0 \mathrm{ml} / \mathrm{min}$; eluent, $0.1 \%$ phosphoric acid in $\mathrm{H}_{2} \mathrm{O}-\mathrm{MeOH}(96: 4, \mathrm{v} / \mathrm{v})$; detection, $290 \mathrm{~nm}$. Percent inhibition was calculated according to the following equation: inhibition $(\%)=[$ (peak area of uric acid in the control experiment) - (peak area of uric acid in the sample experiment)] x $100 /$ ( peak area of uric acid in the control experiment).

\section{Results}

Propolis from the stingless bee, Tetragonula aff. biroi, was extracted with $70 \%$ EtOH by stirring at room temperature. The extract was suspended in $\mathrm{H}_{2} \mathrm{O}$ and successively partitioned with $n$-hexane and EtOAc to yield $n$-hexane-, EtOAc-, and $\mathrm{H}_{2} \mathrm{O}$-soluble fractions, respectively. Further separation and purification of the $n$-hexane and EtOAc factions led to the identification of three new compounds (1-3) and ten known compounds (4-13) (Figure 1 and 2 ). The structures of all isolated compounds were identified by 1D and 2D NMR, MS, ECD, and opticalrotation spectra. 


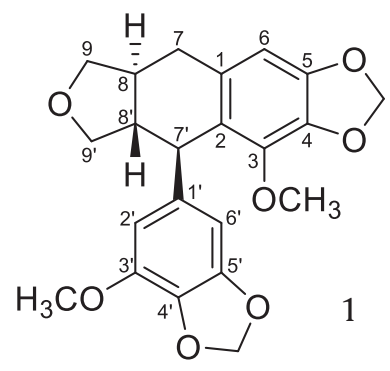<smiles>COc1cc([C@@H]2c3c(cc(OC)c(OC)c3OC)C[C@@H]3COC[C@H]32)cc2c1OCO2</smiles><smiles>[R]c1c(O)c2c(c([R])c1OC)O[C@H](C)[C@H](C)C2=O</smiles><smiles>[R]CCCCCCC(C)CC(=O)O</smiles><smiles>[R]C(C)(O)CC(C)(C)C</smiles>
4<smiles>CCCCCC(C)CC(=O)O</smiles><smiles>CCC=C(C)C</smiles><smiles>[R]c1c(O)c([R])c2oc(-c3ccc(O)c([CH+]C=C(C)C)c3)c(O)c(=O)c2c1O</smiles><smiles>[R]C(C)/C(F)=C/CC</smiles><smiles>CCCCCC(CC(=O)O)c1c(O)c(CC=C(C)C)c2c(c1OC)C(=O)[C@H](C)[C@@H](C)O2</smiles><smiles>COc1cc(-c2oc3cc(O)cc(O)c3c(=O)c2O)ccc1O</smiles><smiles>CC(/C=C/C1(O)C(F)=CC(=O)CC1(C)C)=C\C(=O)O</smiles><smiles>CCCCCC(CC(=O)O)c1c(O)c2c(c3c1O[C@H](C)[C@H](C)C3=O)OC(C)(C)C=[C]2</smiles>

12<smiles>CC1=CC(=O)CC(C)(C)C1(O)/C=C/C(C)=C\C(=O)O</smiles>

Figure 1. Structures of the compounds from stingless bee propolis collected on South Sulawesi, Indonesia

Compounds 1 and 2 were determined to be new podophyllotoxin derivatives. Compound 1 was obtained as a white powder. Its molecular formula was determined to be $\mathrm{C}_{22} \mathrm{H}_{22} \mathrm{O}$ by HRESIMS (calcd. for $\mathrm{C}_{22} \mathrm{H}_{23} \mathrm{O}_{7}: 399.1444[\mathrm{M}+\mathrm{H}]^{+}$). The absolute configurations of the stereocenters in 1 were also determined as $8 S, 7 ' R, 8$ 'S with a Flack parameter of $-0.09(5)$ by single-crystal X-ray diffraction with $\mathrm{Cu} \mathrm{K \alpha}$ radiation. Based on the spectroscopic and crystallographic analyses, 1 was determined to be a new podophyllotoxin derivative and assigned the name "sulabiroin A". 


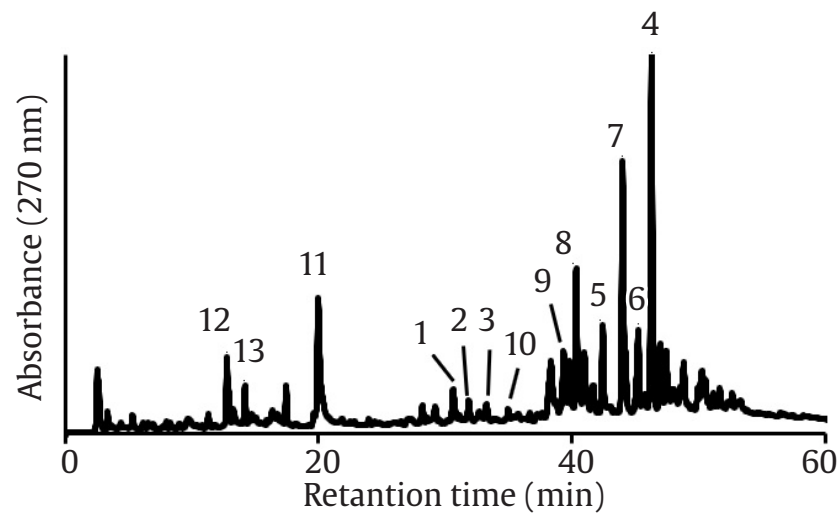

Figure 2. HPLC profiles of ethanol extracts of the yellow resin from surface of propolis from Indonesian stingless bees (Tetragonula aff. biroi); for peak assignment numbers, refer to Figure 1

Compound 2 was obtained as a colorless oil. Its molecular formula was determined to be $\mathrm{C}_{23} \mathrm{H}_{26} \mathrm{O}_{7}$ by HRESIMS (calcd. for $\mathrm{C}_{23} \mathrm{H}_{27} \mathrm{O}_{7}: 415.1757[\mathrm{M}+\mathrm{H}]^{+}$). The experimental ECD spectrum of 2 showed one large positive cotton effect at $220 \mathrm{~nm}$, and its $\lambda_{\max }$ and band shape were almost identical with those of 1. Furthermore, the calculated ECD spectrum of the $\left(8 S, 7^{\prime} R, 8^{\prime} S\right)$ diastereoisomer of 2 was in good accordance with the experimental one. Hence, the absolute configuration of 2 was established as $\left(8 S, 7^{\prime} R, 8^{\prime} S\right)$. Based on the various spectroscopic analysis, 2 was also determined to be a new podophyllotoxin derivative and assigned the name "sulabiroin B".

Compound 3 was obtained as a brown oil. Its molecular formula was determined to be $\mathrm{C}_{25} \mathrm{H}_{38} \mathrm{O}_{7}$ by HRESIMS (calcd. for $\mathrm{C}_{25} \mathrm{H}_{37} \mathrm{O}_{7}: 449.2539[\mathrm{M}-\mathrm{H}]^{-}$). To determine the relative configuration between $\mathrm{C}-2$ and $\mathrm{C}-3$ of 3 , the proton coupling constant between these protons was compared with those of calopolyanic acid (cis-configured C-2 and C-3) and isocalopolyanic acid (trans-configured C-2 and C-3), which have the same 2,3-dimethylchroman-4-one skeleton as 3 (Wang et al. 2010). Since the proton coupling constant between $\mathrm{H}-2$ and $\mathrm{H}-3$ in $3 \mathrm{~J}=$ $11.2 \mathrm{~Hz}$ ) was closer to that of isocalopolyanic acid $(J$ $=11.6 \mathrm{~Hz})$ than that of calopolyanic acid $(J=3.1 \mathrm{~Hz})$, the relative configuration between $\mathrm{C}-2$ and $\mathrm{C}-3$ in 3 was determined to be a trans. Based on the various spectroscopic analyses, 3 was determined to be a new chromanone derivative, and assigned the name "2',3'-dihydro-3'-hydroxypapuanic acid".

The ${ }^{1} \mathrm{H}$ NMR spectra of $4,5,6$, and 7 revealed proton coupling constants $(J)$ between $\mathrm{H}-2$ and $\mathrm{H}-3$ of 11.4 (4), 11.3 (5), 3.3 (6), and $13.9 \mathrm{~Hz}(7)$. The relative configurations between $\mathrm{C}-2$ and $\mathrm{C}-3$ in the 2,3-dimethylchroman-4-one skeletons were determined to be 4:trans, 5:trans, 6:cis, and 7:trans from the above-mentioned proton coupling constants between $\mathrm{H}-2$ and $\mathrm{H}-3$.

From the spectroscopic analysis and comparisons with literature data, the known compounds were identified to be isopapuanic acid (6) (Stout et al. 1968), isocalopolyanic acid (7) (Wang et al. 2010), glyasperin A (8) (Zeng et al. 1992), broussoflavonol F (9) (Zheng et al. 2008), (2S)-5,7-dihydroxy-4'methoxy-8-prenylflavanone (10) (Parsons et al. 1993), isorhamnetin (11) (Lee et al. 2008), (1'S)-2trans,4-trans-abscisic acid (12) (Ferreres et al. 1996; Kikuzaki et al. 2004), and (1'S)-2-cis,4-trans-abscisic acid (13) (Ferreres et al. 1996; Kikuzaki et al. 2004).

Since 1 and 11 were isolated as in high yields, they were evaluated for XO inhibitory activity. As a result, 1 exhibited little XO inhibitory activity, whereas 11 showed potent XO inhibitory activity, with an $\mathrm{IC}_{50}$ value of $3.9 \mu \mathrm{M}$. This $\mathrm{IC}_{50}$ value is close to that allopurinol, which is used as anti-gout drug $\left(\mathrm{IC}_{50}: 1.0\right.$ $\mu \mathrm{M})$.

\section{Discussion}

As for the absolute configurations of chromanone derivatives, the optical rotations of (-)-papuanic acid (4) and (-)-isocalolongic acid (5) did not agree with the previously reported optical rotations, as described below. The originally isolated papuanic acid was reported to have an $[\alpha]_{D}$ of $+175^{\circ}$ (c 0.191, EtOH, $[\phi]_{589}$ $+350^{\circ}$ converted using the followed equation: $\alpha=$ $\phi / 2$ ) (Stout et al. 1968), while $[\alpha]_{\mathrm{D}}^{28}$ of our (-)-papuanic acid (4) was $-39.4^{\circ}$ (c 0.191, EtOH). In addition, the originally isolated isocalolongic acid was reported to have an $[\alpha]_{D}$ of $+28^{\circ}\left(c 1.9, \mathrm{CHCl}_{3}\right.$ ) (Guerreiro et al. $1973)$, while the $[\alpha]_{\mathrm{D}}^{29}$ of our (-)-isocalolongic acid (5) was $-72.4^{\circ}\left(c 0.70, \mathrm{CHCl}_{3}\right)$. The $[\alpha]_{D}$ of apetalic acid, with the same chromanone skeleton, was originally reported to be $+28.4^{\circ}$ (c 2.56, $\mathrm{CHCl}_{3}$ ) (Govindachari et al. 1968), while the later-isolated apetalic acids were reported to have $[\alpha]_{\mathrm{D}}^{25}$ values of $-29.4^{\circ}\left(\mathrm{c} 0.15, \mathrm{CHCl}_{3}\right)$ (Hay et al. 2003) and $-53.0^{\circ}$ (c 1.50, $\mathrm{CHCl}_{3}$ ) (HuertaReyes et al. 2004). Because the configuration of the C-13 of the chromanone derivatives was neglected, these data suggest that these compounds have different absolute chromanone structures.

To the best of our knowledge, the chromanone derivatives have not been isolated from any other propolis (Figure 3). Component analysis of Indonesian propolis from stingless bees (Tetragonula aff. biroi) collected on South Sulawesi suggested that the plant origin of the propolis was a new type. 


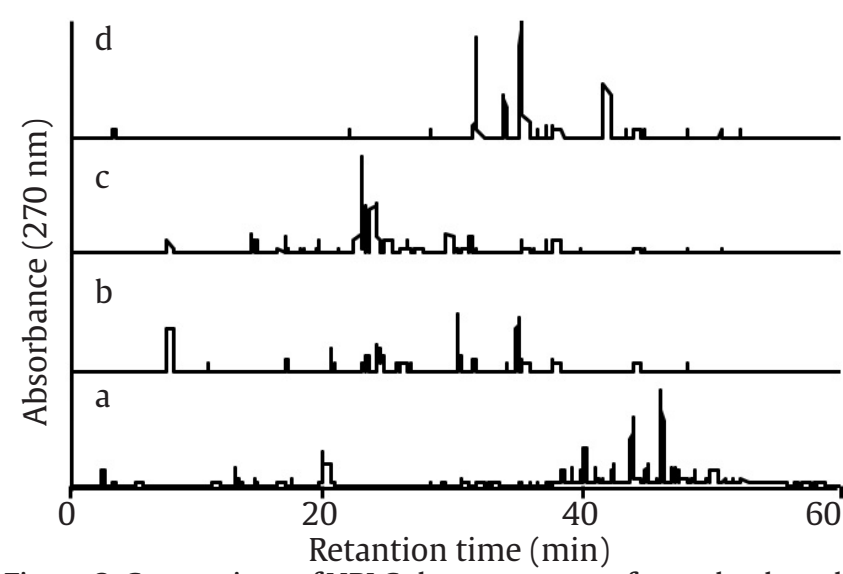

Figure 3. Comparison of HPLC chromatograms for each ethanol extract from propolis. (a) Indonesian stingless bees, (b) Baccharis dracunculifolia type (Brazil), (c) Populus type (Uruguay), and (d) Macaranga tanarius type (Okinawa, Japan)

\section{Acknowledgements}

We wish to thank Dr. Takashi Kikuchi, Rigaku Corporation, Japan for X-ray structure analysis and Satomi Onoue and Hideyuki Sato, Graduate School of Integrated Pharmaceutical and Nutritional Sciences, University of Shizuoka, Japan for the measurements of ECD spectra. This work was supported by JSPS KAKENHI Grant Number JP15K07436 and the World Class Professor Program (No. 123.3/D2.3/KP/2018) from the Ministry of Research, Technology and Higher Education of the Republic of Indonesia.

\section{References}

Bankova VS et al. 2000. Propolis: recent advances in chemistry and plant origin. Apidologie 31:3-15.

Bankova V, Popova M. 2007. Propolis of stingless bees: a promising source of biologically active compounds. Pharmacogn Rev 1:88-92.

Banskota AH et al. 2001. Recent progress in pharmacological research on propolis. Phytother Res 15:561-571.

Chinh TX, Sommeijer MJ. 2005. Production of sexuals in the stingless bee Trigona (Lepidotrigona) ventralis flavibasis Cockerell (Apidae, Meliponini) in northern Vietnam. Apidologie 36:493-503.

Ferreres F et al. 1996. Natural occurrence of abscisic acid in heather honey and floral nectar. J Agric Food Chem 44:2053-2056.

Frisch MJ et al. 2013. Gaussian 09, Revision D.01. Wallingford: Gaussian Inc.

Govindachari TR et al. 1968. Structure of apetalic acid. Tetrahedron 24:6411-6415.

Guerreiro E et al. 1973. Chromanones from the bark of Calophyllum recedens. Phytochemistry 12:185-189.
Hay AE et al. 2003. Antifungal chromans inhibiting the mitochondrial respiratory chain of pea seeds and new xanthones from Calophyllum caledonicum. Planta Med 69:1130-1135.

Honda S et al. 2017. Conversion to purpurogallin, a key step in the mechanism of the potent xanthine oxidase inhibitory activity of pyrogallol. Free Radic Biol Med 106:228-235.

Huerta-Reyes M et al. 2004. HIV-1 inhibitory compounds from Calophyllum brasiliense leaves. Biol Pharm Bull 27:1471-1475.

Ishikawa Y. 2013. A script for automated 3-dimentional structure generation and conformer search from 2-dimentional chemical drawing. Bioinformation 9:988-992.

Kikuzaki $\mathrm{H}$ et al. 2004. Abscisic acid related compounds and lignans in prunes (Prunus domestica L.) and their oxygen radical absorbance capacity (ORAC). J Agric Food Chem 52:344-349.

Kumazawa S et al. 2002. Studies of the constituents of Uruguayan propolis. J Agric Food Chem 50:47774782 .

Kumazawa S et al. 2003. Direct evidence for the plant origin of Brazilian propolis by the observation of honeybee behavior and phytochemical analysis. Chem Pharm Bull 51:740-742.

Kumazawa S et al. 2004a. A new prenylated flavonoid from propolis collected in Okinawa, Japan. Biosci Biotechnol Biochem 68:260-262.

Kumazawa S et al. 2004b. Antioxidant activity of propolis of various geographic origins. Food Chem 84:329-339.

Lee $\mathrm{E}$ et al. 2008. Effects of hydroxy and methoxy substituents on NMR data in flavonols. Bull Korean Chem Soc 29:507-510.

Lotfy M. 2006. Biological activity of bee propolis in health and disease. Asian Pac J Cancer Prev 7:22-31.

Marcucci MC. 1995. Propolis: chemical composition, biological properties and therapeutic activity. Apidologie 26:83-99.

O'Boyle NM et al. 2011. Open babel: an open chemical toolbox. J Cheminform 3:1-14.

Parsons IC et al. 1993. New triterpenes and flavonoids from the leaves of Bosistoa brassii. J Nat Prod 56:46-53.

Salantino A et al. 2011. Propolis research and the chemistry of plant products. Nat Prod Rep 28:925-936.

Sforcin JM, Bankova V. 2011. Propolis: is there a potential for the development of new drugs? J Ethnopharmacol 133:253-260.

Sheldrick GM. 2015. Crystal structure refinement with SHELXL. Acta Cryst 71:3-8.

Stewart JJ. 2013. Optimization of parameters for semiempirical methods VI: more modifications to the NDDO approximations and re-optimization of parameters. J Mol Model 19:1-32.

Stout GH et al. 1968. Calophyllum products. IV. Papuanic and isopapuanic acids. J Org Chem 33:4191-4200.

Vainio MJ, Johnson MS. 2007. Generating conformer ensembles using a multiobjective genetic algorithm. J Chem Inf Model 47:2462-2474. 
Wang $\mathrm{H}$ et al. 2010. Chromanone derivatives from the pericarps of Calophyllum polyanthum. Helv Chim Acta 93:2183-2188.

Zeng L et al. 1992. Phenolic constituents of Glycyrrhiza species. Part 8. Four new prenylated flavonoids, glyasperins A, B, C, and D from the roots of Glycyrrhiza aspera. Heterocycles 34:575-587.
Zheng ZP et al. 2008. Tyrosinase inhibitors from paper mulberry (Broussonetia papyrifera). Food Chem 106:529-535. 